\title{
Os Benefícios do Custeio Baseado em Atividades na Gestão de Custos de Uma Empresa Agrícola
}

\author{
Euselia Paveglio Vieira \\ Mestrado em Contabilidade pela Fundação Visconde de Cairu \\ Professora da Universidade Regional do Noroeste do Estado do Rio Grande do Sul - \\ UNIJUI \\ Rua do Comércio 3000. Universitário. ljuí/RS. CEP: 98700-000 \\ E-mail: euselia@unijui.edu.br
}

Diego Rafael Winck

Universidade Regional do Noroeste do Estado do Rio Grande do Sul - UNIJUI

Rua do Comércio 3000. Universitário. ljuí/RS. CEP: 98700-000

E-mail:diegow@hotmail.com

Roselaine Filipin

Mestrado em Ciências Contábeis pela Fundação Universidade Regional de Blumenau -

FURB

Professora da Universidade Regional do Noroeste do Estado do Rio Grande do Sul -

UNIJUI

Rua do Comércio 3000. Universitário. ljuí/RS. CEP: 98700-000

E-mail:Roselaine.filipin@unijui.edu.br

\section{RESUMO}

O artigo relata um estudo que tem como tema o Custeio Baseado em Atividades (ABC), cujo objetivo principal foi apontar os seus benefícios na gestão de custos de uma empresa agrícola. Para tanto, foi efetuada uma revisão da literatura a respeito dos conceitos ligados ao tema do estudo e a atividade agrícola. Em seguida foi apresentada a metodologia utilizada na pesquisa, a qual é classificada como aplicada, documental e estudo de caso, fazendo-se uso para a coleta de dados de entrevista não formal e verificação de documentos. Os resultados obtidos indicam as vantagens encontradas com a utilização do custeio $A B C$, que considerou formas de direcionadores de custos diferenciadas para os custos indiretos, como as horas máquinas utilizadas na realização das atividades da produção agrícola. Isso permitiu concluir que este método traz benefícios aos gestores de empresas agrícolas para a análise das atividades que demandam mais recursos, podendo torná-las mais eficientes, investindo em treinamento de pessoas e aplicando novas tecnologias de mecanização.

Palavras-chave: Método ABC. Gestão. Custos. Informações. Resultados.

The Benefits of Activity Based Costing in Costs Management of a Farm Company 


\section{ABSTRACT}

The article reports a study involved the Activity Based Costing (ABC), whose main objective was identify its benefits in costs management on an agricultural enterprise. Therefore, a literature review was conducted on the concepts related to the study subject and agricultural activity. After that, the methodology used in the research was presented, and is classified as applied, documentary and case study, making use of non-formal interview for the data collection and document verification. The results indicate the advantages found with the use of $A B C$, which considered ways to drivers of different costs for indirect costs such as time machines in performing activities of agricultural production. This showed that this method is beneficial to managers of agricultural companies for the analysis of activities that require more resources, making them more efficient by investing in training people and applying new mechanization technologies.

Key-words: Method ABC. Management. Costs. Information. Result.

\section{INTRODUÇÃO}

Para alcançar o lucro em organizações agrícolas, não se utiliza apenas como base o valor de venda dos produtos, já que o preço obedece a diversos fatores externos à organização, sendo estes a base de preços para os produtos, que são as cotações de mercado, não cabendo à organização a sua precificação e sim, acompanhar o desempenho entre o preço estabelecido e os custos apurados na produção, podendo-se dizer que a busca da obtenção de lucro é mais facilmente alcançada com processos qualificados de gestão de custos.

Notória é a atual necessidade de avaliações de custos de produção, seja por cultura ou por hectare, que pode ser transformado em custo unitário quando dividido pela produtividade obtida por hectare. Para quantificar o esforço financeiro despendido na produção é necessário utilizar sistemas de acumulação de custos que contam com modelos de determinação e apuração destes gastos.

Há neste sentido, a gestão de custos que proporciona, juntamente com o sistema de custos, a identificação de gastos com a produção, para que com base nestes dados possam ser realizadas classificações, análises, avaliações, controles e planejamentos, 
consequentemente, transforma-se num importante instrumento de gestão, como fonte primária e básica para a tomada de decisão importante ressaltar que a gestão de custos não se aplica somente às indústrias, sendo que é possível calcular custos comerciais, de serviços, agrícolas, entre outros.

O artigo apresenta em sua estrutura, como área de conhecimento contemplada, a Gestão de Custos. O objetivo é descrever os benefícios entregues pelo método de custeio baseado em atividades na gestão de custos das culturas de soja, milho e algodão. Acredita-se que, com a utilização dos resultados calculados pelo custeio baseado em atividades, as demonstrações dos valores dos recursos alocados são mais precisas, evitando as atribuições arbitrárias que podem ocorrer com o cálculo de custos por hectare produzido.

Para atender este propósito, inicialmente, efetuou-se uma revisão da bibliografia abordando os principais conceitos imprescindíveis ao entendimento do estudo ora relatado. Posteriormente, são descritas as características que precisam ser encontradas na empresa que queira utilizar o modelo $A B C$, as etapas a serem seguidas para implementação e as informações gerenciais obtidas, finalizando com as vantagens e desvantagens relacionadas a este modelo de custeio, que foi a base para a realização do estudo na propriedade agrícola.

Esta pesquisa se classifica como aplicada, quanto aos seus objetivos é exploratória e descritiva. Pelo aspecto dos procedimentos adotados, a pesquisa caracteriza-se como um estudo de caso, pois se concentra em uma única empresa e suas conclusões limitam-se ao contexto do objeto de estudo, com a utilização de ferramentas para a coleta de dados a entrevista não formal a verificação de documentos.

$\mathrm{Na}$ análise dos resultados pode-se constatar que a empresa agrícola que possui mais de um cultivo, ao utilizar formas de alocação de gastos diretos que utilizem critérios como a área plantada pode ter demonstrado, gerencialmente, um custo distorcido, já que critérios deste tipo não levam em consideração a complexidade das atividades existentes no processo de produção. 
Após a realização do estudo pode-se concluir que a inclusão de parte ou a totalidade dos preceitos do custeio baseado em atividades na geração de informações de custos na empresa agrícola é benéfica, já que pode demonstrar aos gestores, com o uso de relatórios apropriados, as atividades do processo de produção que mais demandam recursos da empresa.

\section{CUSTEIO BASEADO EM ATIVIDADES}

O Custeio Baseado em Atividades já era conhecido e usado por contadores em 1800 e início de 1900, e registros históricos mostram o seu uso na década dos anos 60, segundo Nakagawa (2001). Já Bornia (2010) relata que na década de 70 e início da década de 80 , as empresas do ramo de automação enfrentavam dificuldades em vender seus produtos, devido ao fato que gerentes com desejos de automatizar seus processos não conseguiam justificar o grande investimento necessário para a compra de equipamentos, visto que a análise dos custos tradicionalmente empregada na época mostrava o caminho contrário, pelo motivo que fatores intangíveis, tais como o aumento da qualidade, pela maior padronização e aumento da flexibilidade, não eram considerados.

Surgem então grupos de discussões que apontam, entre outras características do sistema de custos das empresas modernas, a presença do custeio baseado em atividades. Que, segundo Nakagawa o $A B C$ é algo muito simples, "trata-se de uma metodologia desenvolvida para facilitar a análise estratégica de custos relacionados com as atividades que mais impactam o consumo de recursos de uma empresa" Nakagawa (2001, p.40).

Pode se definir como uma atividade, segundo Nakagawa (2001, p. 42) "um processo que combina, de forma adequada, pessoas, tecnologias, materiais, métodos e seu ambiente, tendo como objetivo a produção de produtos". Justificando-se a utilização do conceito de atividade, já que "do ponto de vista do $A B C$, a atividade é uma boa unidade de análise de custos porque: (a) não é tão ampla quanto as funções 
departamentais que, geralmente, constituem-se em centros de custos e (b) não é tão restrita quanto as tarefas" Martins e Rocha (2010, p. 143).

Para que se definam quais são as atividades relevantes dentro do processo de produção dos bens ou serviços, segundo Martins e Rocha (2010) é preciso observar diretamente os processos e entrevistar as pessoas que executam as atividades, bem como seus superiores e após, segregar as atividades se elas tiverem custo relevante; tiverem potencial de diferenciação; tiverem direcionador de custos próprios (específico) e gerarem bem ou serviço para o qual exista mercado.

Em resumo, o Custeio Baseado em Atividades possui as seguintes principais indicações e características, conforme Martins e Rocha (2010, p. 162).

a) Deve ser utilizado desde o processo de planejamento e orçamento, não apenas ex post facto;

b) Deve ser utilizado como método de análise, não como sistema de acumulação de custos;

c) Deve ser utilizado em análises pontuais, periódicas, não como sistema recorrente;

d) Requer a adoção de padrões e deve ser consistente com o sistema orçamentário;

e) É um instrumento gerencial, não societário ou tributário;

f) Não aloca custos de ociosidade aos produtos;

g) Adota o conceito de variabilidade de custos em relação a vários direcionadores, não apenas volume de produção.

Assim, o critério $A B C$ é uma tentativa a mais de encontrar o custo verdadeiro, que segundo Leone e Leone (2010, p. 256) não há nenhum sistema que demonstre este custo verdadeiro de um produto ou serviço salvo se a empresa fabricar apenas um produto ou realizar apenas um serviço, isso levando-se em consideração o problema da alocação dos custos comuns, porque existem dezenas de outros fatores que concorrem para que os custos verdadeiros jamais existam, tenta-se com os métodos existentes, alcançar os melhores resultados. 
Dentre as justificativas para a utilização do custeio por atividades na atividade agrícola, pode-se relatar que hoje, a maior parte dos gastos na produção agrícola é calculada diretamente para o produto. No entanto, uma parte do custo não pode onerar diretamente qualquer cultivo. Estes são os custos indiretos, como: energia, combustíveis, custos de manutenção de equipamentos, limpeza, custos de depreciação e amortização, prêmios de seguros, custos de água outros, que são divididos entre diferentes cultivos, com a ajuda de algum método de alocação, mais frequentemente de acordo com o hectare plantado.

De acordo com Nakagawa (2001, p.62) "pelos sistemas tradicionais de controle gerencial, tem-se constatado que as análises de variações de preços, eficiência, gastos e volume têm sido prejudicadas devido às grandes distorções de custos". Isso ocorre, conforme Nakagawa (2001, p.62), "quando estes são calculados pelo custeio baseado em volume (absorção ou variável), comparados com os calculados pelo ABC". O autor também elenca as principais causas destas distorções, sendo:

- Diversidade nos volumes de produção e vendas;

- Diversidade nos tamanhos, cores e outras especificações dos produtos;

- Diversidade na complexidade dos produtos e seu mix de vendas;

- Diversidade nos materiais utilizados e números de componentes dos produtos;

- Diversidade nos tempos e formas de setups e changeovers. (NAKAGAWA, 2001, p.62).

A aplicação deste modelo de custeio é justificada em organizações agrícolas que mantém mais de um tipo de cultura e os produtos diferem em complexidade, escala de produção e quantidade de gastos indiretos aplicados. A tarefa mais difícil no cálculo dos custos de produção agrícola é a determinação do valor real alocado a cada cultivo, sendo o cálculo de custos em razão da atividade o método mais complicado, embora possa ser considerado o mais preciso dos processos de alocação das despesas gerais. 


\subsection{Exigências Para a Possibilidade de Implantação}

O Custeio Baseado em Atividades, quando bem utilizado, pode demonstrar a possível existência de ineficiência em atividade do processo de produção. Assim, para que este modelo de custeio tenha sucesso, é necessário, primeiramente uma mudança organizacional, ou seja, uma mudança na maneira de pensar dos funcionários como sua aceitação.

Como dito por Nakagawa, (2001, p.62) em vez de apenas buscar novas formas de rateios para os custos indiretos, como muitas empresas já estão até mesmo fazendo, o $A B C$ busca facilitar, na verdade, a implementação de um processo de mudança de atitudes na empresa, ou seja, o $A B C$ deve ser visto como um agente de mudanças para a mente humana.

A implantação com sucesso do modelo $A B C$ na empresa, segundo Martins e Rocha (2010, p. 155) pode ser facilitada pela existência dos seguintes sistemas: de padrões; de orçamento; de contabilidade eficiente e eficaz; de custeio recorrente eficiente e eficaz etc.

No entanto os mesmos autores listam empecilhos que podem ameaçar o sucesso da implantação do modelo, como seguem: 
a) Dificuldade na seleção das atividades relevantes;

b) Seleção de quantidade excessiva de atividades;

c) Dificuldade no processo de contabilização das transações, documento a documento, por atividades; muitas vezes, uma proporção relevante dos custos não apresenta condições de contabilização por atividade. Isso confirma a ideia de que é praticamente inviável alocar todos os custos a todas as atividades;

d) Dificuldade na formação de grupos de custos homogêneos e na identificação dos respectivos direcionadores de custos;

e) Dificuldade de formar séries temporais de grupos de custos e seus prováveis direcionadores, para realizar os testes estatísticos de sua validação;

f) Necessidade de coletar e de contabilizar muitos dados manualmente;

g) Presença de fatores institucionais adversos, tais como discursos concorrentes, conflito de interesses e outros;

h) Dificuldade para identificar o nível de capacidade normal das atividades;

i) Criação de sistemas adicionais, planilhas e time sheets trabalhosos etc. Martins; Rocha (2010, p. 155).

Não há necessidade de utilizar o método de forma contínua, como sugerido pelos autores:

O Custeio por Atividades deve ser utilizado periodicamente, de forma suplementar ao sistema de custeio recorrente da empresa, não em sua substituição; sua função é possibilitar análises a intervalos regulares de tempo. O sistema recorrente de custeio, seja pelo Absorção ou pelo Variável, assim como o orçamento, é usado para dar suporte a decisões corriqueiras, enquanto o $A B C$ requer intervenções e decisões menos frequentes, como, por exemplo, eliminação de atividades que não estejam agregando valor, Martins; Rocha (2010, p. 160).

Para a implantação do Custeio Baseado em Atividades na organização é necessário ser percorridas algumas etapas, como o sugerido por Nakagawa (2001), 
precisando ter o convencimento de que o $A B C$ será um agente de mudanças; verificar a adequacidade do $A B C$ às necessidades da organização; disponibilidade e desejo de investir no $A B C$ e uma estratégia de implementação do $A B C$ que deve estabelecer que os relatórios gerados pelo $A B C$ devem ser úteis; que o modelo $A B C$ da empresa deve ser sempre atualizado, que os sistemas de suporte ao $A B C$ devem ser sempre melhorados; que cada gerente deve ter $O A B C$ que atenda a suas necessidades específicas e que os usuários devem receber educação continuada em $A B C$.

A primeira utilidade de um relatório de custos elaborado sob o método $A B C$ é propiciar a informação do custo das atividades relevantes; isso por si só, ainda que não se tenha a alocação do custo das atividades para os produtos, já costuma provocar surpresa, pois os sistemas de custeio recorrentes, normalmente, reportam os custos por centros de custos ou por departamentos. Além disso, as informações de custos por produtos e por clientes, geradas pelo Custeio Baseado em Atividades, podem ser utilizadas para:

Gestão da capacidade, alinhando os recursos disponibilizados aos demandados;

Gestão do overhead;

Melhoria de processos, eliminando atividades que não agregam valor;

Melhoria de processos, aperfeiçoando as atividades que agregam valor;

Gestão de preços, inclusive preços de transferência;

Análise de lucratividade de produtos;

Identificação de subsídios cruzados entre produtos;

Transformação de produtos deficitários em lucrativos;

Análise de lucratividade de clientes;

Identificação de subsídios cruzados entre clientes;

Transformação de clientes deficitários em lucrativos;

Reposicionamento estratégico em relação a determinados produtos;

Revisão da política de atendimento a determinados clientes;

Identificação, gestão e mensuração de custos de qualidade;

Planejamento e gestão estratégica;

Planejamento operacional de longo prazo; 
Mensuração de eficiência e produtividade no desempenho das atividades;

Análise de custos de longo prazo dos produtos;

Repasse de custos pela realização de atividades geradoras de serviços compartilhados por várias unidades da empresa ou por várias empresas de um conglomerado;

Prestação de contas relativas à realização de projetos financiados por doadores públicos ou privados;

Reembolso de custos pela realização de serviços hospitalares e outros, prestados por conta de órgãos governamentais etc. Martins e Rocha ( 2010, p. $160,161)$.

Quando se diz que o $\mathrm{ABC}$ é uma ferramenta que auxilia os gerentes a descobrirem as rotas do consumo dos recursos da empresa, busca-se, na realidade, colocar à sua frente uma informação muito importante para suas decisões. "Baseado nas próprias atividades e produtos que os gerentes conhecem muito bem, 0 ABC mostra-Ihes com clareza e transparência os custos dessas atividades e produtos" Nakagawa (2001, p. 62).

\subsection{Custeio Baseado em Atividades na Empresa Agrícola}

A "agricultura é definida como a arte de cultivar a terra. Arte essa decorrente da ação do homem sobre o processo produtivo para a satisfação de suas necessidades básicas" (SANTOS; MARION; SEGATTI, 2009, p. 13). Pode-se dizer que é uma forma de utilização e modificação do meio natural e que vai desde a preparação do solo e plantio, até à colheita e armazenamento, passando pela conservação e irrigação das culturas, combate a pragas e a diversos outros tipos de influências naturais e ainda as atividades de melhoria das espécies de vegetais e animais. Estas atividades podem ser efetuadas de uma forma mais simples, utilizando o trabalho manual e o auxílio da força animal, ou de uma forma mais complexa e moderna, com um elevado grau de mecanização e recorrendo a tecnologias avançadas.

O Custeamento baseado em atividades tem uma de suas razões de aparecimento, segundo Leone e Leone (2010, p. 250), devido a evolução tecnológica, 
que alterou bastante a composição dos custos dos fatores de produção, tornando os custos indiretos de fabricação mais significativos e menos significativos os custos do fator mão de obra direta. Observa-se também na literatura que o custeio $A B C$ tem sua maior aplicação em atividades industriais, por motivos de vários produtos diferentes produzidos em uma linha de montagem e da variedade de atividades aplicadas na fabricação destes produtos.

Por outro lado, a empresa agrícola demanda relatórios detalhados do sistema de informação, que podem ser obtidos com a utilização do $A B C$, para que estes sejam utilizados de maneira eficiente. Segundo Santos; Marion; Segatti (2009, p. 128) este nível de detalhe não é comum às empresas industriais, mas na produção agrícola é vital, já que uma das diferenças significativas entre a indústria e a agricultura é o aspecto do planejamento de curto prazo, enquanto na indústria é possível seguir rigidamente as variações na demanda e executar mudanças na produção, na agricultura com culturas de curto prazo ou permanentes, as mudanças são elaboradas na melhor das hipóteses em meses ou, o que é mais comum, em anos.

Nas empresas de produção de produtos agrícolas, conforme Santos; Marion; Segatti (2009, p. 129) "a fixação dos preços destes produtos é realizada à base de preço de mercado". Por esta razão o sistema de contabilidade de custos, na empresa agrícola, não incorpora considerações sobre a receita, e por não haver controle sobre cálculos de apreçamento dos seus produtos, o custeio por atividades dará ênfase à identificação de custeamento e aos controles.

Então, para a agricultura, já que o custeio baseado em atividades parte da premissa de que os produtos consomem atividades e que estas atividades é que consomem os recursos e trazendo este conceito para a realidade da empresa agrícola, pode-se analisar que o custeio baseado em atividades poderá gerar relatórios mais condizentes com a realidade, considerando que uma cultura com área menor pode exigir um esforço maior de trabalho da estrutura de apoio do que outra cultura com maior área. 


\section{METODOLOGIA}

No que tange aos aspectos metodológicos desta pesquisa, ela objetiva a produção de artigo técnico-científico, fundamentado teórica e tecnicamente na modalidade de pesquisa bibliográfica com aprofundamento de temas específicos. Existem diferentes classificações de tipo de pesquisa, estando relacionadas com as peculiaridades das diferentes áreas do conhecimento. Sob o ponto de vista de sua natureza, foi classificada como Pesquisa Aplicada, pois objetiva gerar informações para aplicação prática dirigido à solução da problemática em estudo. "A pesquisa aplicada é fundamentalmente motivada pela necessidade de resolver problemas concretos, mais imediatos, ou não" (VERGARA, 2004, p. 47). No que se refere aos objetivos, classificase como Pesquisa Exploratória, que segundo Gil (2002, p. 41) "têm como objetivo proporcionar maior familiaridade com o problema, com vistas a torná-lo mais explícito ou a constituir hipóteses". Esta pesquisa é "desenvolvida quando se tem pouco conhecimento a respeito de determinado assunto ou aspecto dele e, geralmente pressupõe uma fase de trabalho de campo" (MARION; DIAS; TRALDI, 2002, p. 62)

Para que se alcance o objetivo esperado da pesquisa, é necessário segundo Gil (2002) que se trace um modelo conceitual e operativo da pesquisa delimita-se os procedimentos adotados com o seu planejamento, principalmente para a sua coleta de dados. Dessa forma, com vistas aos procedimentos técnicos a presente pesquisa classifica-se como uma pesquisa bibliográfica, documental e estudo de caso.

A pesquisa bibliográfica conforme Gil (2002, p. 44) "é desenvolvida com base em material já elaborado, constituído principalmente de livros e artigos científicos". Esta forma de pesquisa descrita por Marion, Dias e Traldi (2002, p. 62) não utiliza relatos de pessoas ou experimentos, no entanto, pode ser utilizada independentemente ou inserida como um levantamento bibliográfico nos demais tipos de pesquisas.

O estudo de caso utilizado nesta pesquisa objetiva retratar o dinamismo da problemática em estudo. Conceituado por Gil (2002, p. 54) como um "estudo profundo e exaustivo de um ou poucos objetos, de maneira que permita seu amplo e detalhado 
conhecimento". Assim, o objeto de estudo proposto nesta pesquisa são os benefícios do modelo de custeio baseado em atividades na empresa agrícola.

Por constar a utilização de relatórios, planilhas de dados, entre outras fontes que não receberam tratamento analítico, a pesquisa é também considerada documental. $A$ pesquisa documental segundo Gil (2002, p. 45) "vale-se de materiais que não recebem ainda um tratamento analítico, ou que ainda podem ser reelaborados de acordo com os objetos da pesquisa". Marion, Dias e Traldi (2002, p. 62) afirmam que as fontes primárias utilizadas na pesquisa se constituem de registros documentais sobre 0 assunto escolhido.

Nesta pesquisa foram utilizados como instrumentos de coleta de dados a observação participativa, a entrevista informal e a verificação de documentos. A observação participativa é aquela que, segundo Vergara (2004, p. 54), o pesquisador está "engajado ou se engaja na vida do grupo ou na situação; é um ator ou um espectador interativo". A mesma autora define a entrevista informal ou aberta como sendo quase uma "conversa jogada fora", mas tem um objetivo específico: coletar os dados de que o pesquisador necessita.

Ainda, utilizou-se como forma de tratamento e análise dos dados: planilhas, relatórios e modelos, da mesma forma, a análise de indicadores e entrevistas realizadas. Estes instrumentos colaboraram para a descrição e análise dos resultados obtidos com a presente pesquisa. Tendo o estudo, em sua estrutura, a presença de um capítulo teórico e um capítulo prático.

\section{ANÁLISE DOS RESULTADOS}

Para o melhor entendimento e análise de custos agrícolas é preciso saber que, muito embora o resultado financeiro da empresa agrícola seja elaborado no calendário de ano-civil, a área plantada e as produtividades são demonstradas em anos-safra. $O$ ano safra, para a empresa agrícola em estudo, compreende o período desde o início do 
plantio (em setembro) até o encerramento da colheita, em meados de agosto do ano seguinte, com o encerramento da colheita do algodão, último produto a ser colhido. Segue a representação deste fluxo:

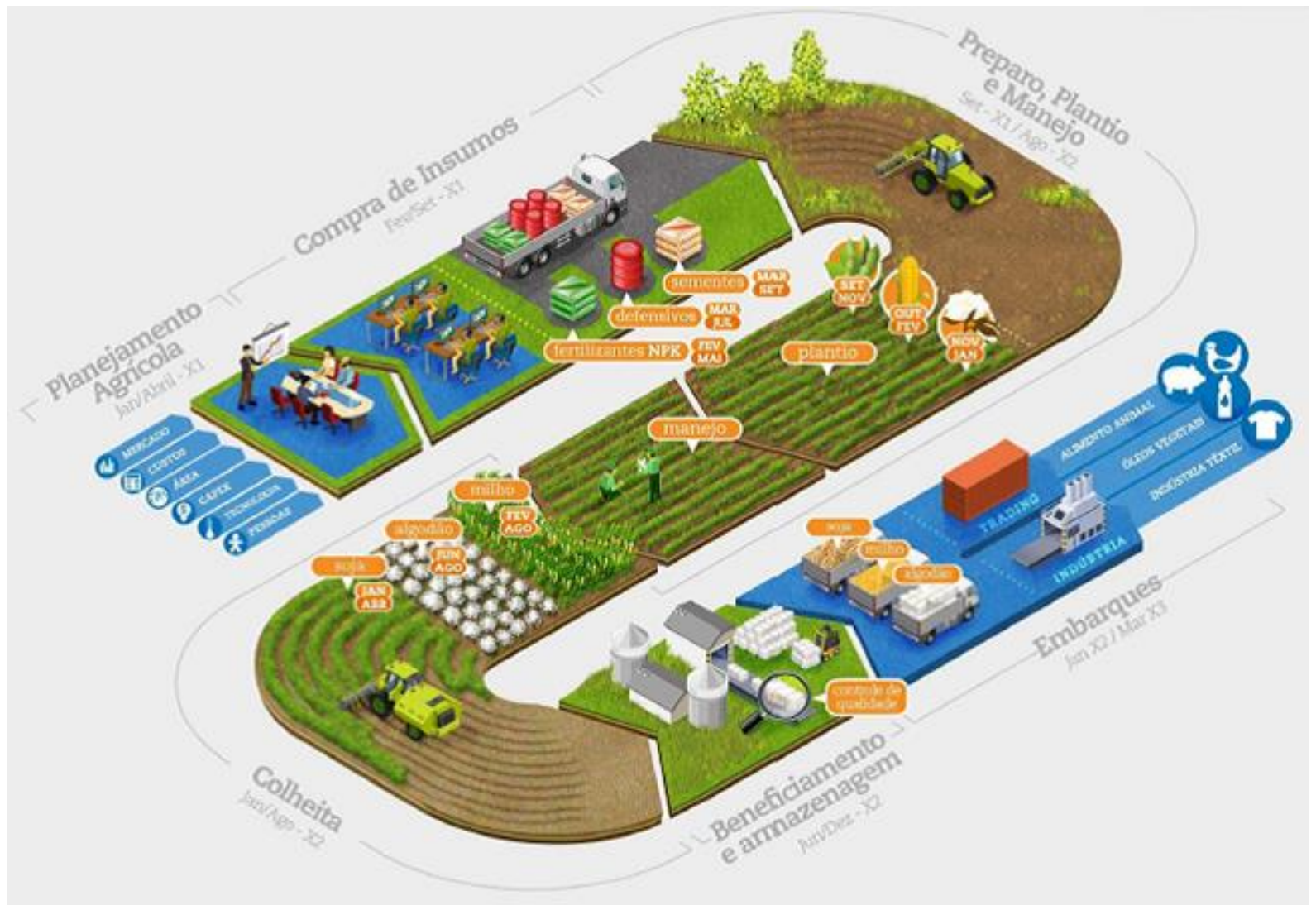

Figura 1: Fluxograma do ano safra.

Fonte: disponível em <http://www.mzweb.com.br/SLCAgricola2009/web/conteudo_pt.asp? idioma=0\&tipo=29140\&submenu=2\&img=29140\&refbread=29097\&conta=28> Acessado em: 19/01/2013.

O passo seguinte é conhecer as diversas operações agrícolas existentes na empresa agrícola, que são as fases necessárias do processo produtivo, de acordo com o tipo de cultura, são essas as etapas que constituem as atividades no custeio $A B C$, onde os custos indiretos tais como, os combustíveis, a depreciação e a conservação de máquinas agrícolas, podem ser apropriados à atividade de acordo com o número de horas máquina utilizados em cada tipo de cultura. Após a definição dos direcionadores 
dos custos indiretos das atividades existentes em cada cultura são acrescidos aos custos diretos para a formação do custo total destas culturas.

$\mathrm{Na}$ sequência, apresentam-se algumas das atividades da empresa agrícola, baseada no roteiro apresentado por Santos; Marion; Segatti (2009):

- Preparo de solo/calagem, com destaque a destoca, limpeza, roçada, correção de solo, gradeação, subsolagem, aração, conservação de solo, sistematização de solo e drenagem;

- Plantio/adubação, com destaque a adubação básica, sulco, coveamento, alinhamento, marcação, semeadura;

- Tratamento fitossanitário, controle de formiga, tratamento de solo, de sementes, fitossanitários e transporte de água;

- Cultivo mecânico, como gradeação, roçada mecânica e manual; aração e limpeza mecânica;

- Cultivo químico, como a aplicação de defensivos (inseticidas, fungicidas e herbicidas);

- Colheita, constituída de colheita, transporte até o ponto de carga, embalagem, carregamento de caminhão e transporte da produção até os silos ou unidades de beneficiamento.

Sendo as atividades de correção e manejo do solo, além do terraceamento e a construção de estradas, quando necessário, são comuns para as três culturas produzidas na empresa em estudo, já que adota-se a rotação de culturas nas áreas, tendo o seu custo compartilhado. Já as atividades de plantio, aplicação de defensivos, adubação de cobertura e colheita, existem nas três culturas, mas os orçamentos são específicos para cada, já que demandam horas máquinas diversas. A manutenção póscolheita existe somente na cultura do algodão, sendo orçada somente para ela.

A partir destas atividades, segue quadros resumos, comparando a apropriação de custos na produção de soja, milho e algodão, pelos critérios atuais utilizados na empresa agrícola, que são baseados no custeio por absorção, utilizando-se como critério de alocação dos custos indiretos o número de hectares de cada atividade, e a 
outra coluna apresenta os resultados utilizando-se da metodologia de custeio $A B C$, baseado nos direcionadores dos custos indiretos:

\begin{tabular}{|c|c|c|c|}
\hline \multicolumn{4}{|c|}{ Custos da Cultura de Soja no Ano Agrícola de 2011/2012 em R\$ } \\
\hline Descrição & $\begin{array}{c}\text { Atual } \\
\text { (absorção) }\end{array}$ & ABC & Diferença \\
\hline Sementes & $1.621 .499,61$ & $1.621 .499,61$ & 0,00 \\
\hline Fertilizantes & $8.403 .731,98$ & $8.403 .731,98$ & 0,00 \\
\hline Defensivos Agrícolas & $4.234 .254,20$ & $4.234 .254,20$ & 0,00 \\
\hline Mão De Obra Variável & $373.213,66$ & $373.213,66$ & 0,00 \\
\hline Transporte, Beneficiamento E Armazenagem & $462.468,08$ & $462.468,08$ & 0,00 \\
\hline Depreciações & $1.623 .294,68$ & $1.623 .294,68$ & 0,00 \\
\hline Amortizacão (corretivos) & $4.686 .644,06$ & $4.686 .644,06$ & 0,00 \\
\hline Arrendamentos & $461.088,72$ & $461.088,72$ & 0,00 \\
\hline Pulverização Aérea & $\mathbf{8 1 1 . 0 4 5 , 6 5}$ & $\mathbf{5 7 7 . 5 4 5 , 8 0}$ & $\mathbf{2 3 3 . 4 9 9 , 8 5}$ \\
\hline Combustíveis E Lubrificantes & $\mathbf{1 . 7 4 0 . 7 3 0 , 1 8}$ & $\mathbf{1 . 2 9 8 . 3 8 0 , 2 3}$ & $\mathbf{4 4 2 . 3 4 9 , 9 5}$ \\
\hline Custos Gerais Variáveis & $\mathbf{2 . 5 0 4 . 1 9 8 , 7 3}$ & $\mathbf{1 . 9 3 7 . 1 2 9 , 3 6}$ & $\mathbf{5 6 7 . 0 6 9 , 3 7}$ \\
\hline Mão De Obra Fixa & $\mathbf{1 . 4 6 7 . 6 4 9 , 7 3}$ & $\mathbf{9 9 6 . 3 4 6 , 5 3}$ & $\mathbf{4 7 1 . 3 0 3 , 2 0}$ \\
\hline Custos Gerais Fixos & $\mathbf{2 . 8 2 6 . 0 7 6 , 5 1}$ & $\mathbf{2 . 2 2 7 . 2 4 8 , 0 1}$ & $\mathbf{5 9 8 . 8 2 8 , 5 0}$ \\
\hline Despesas Administrativas & $\mathbf{1 . 3 2 5 . 1 4 2 , 7 3}$ & $\mathbf{1 . 0 4 9 . 4 8 6 , 2 1}$ & $\mathbf{2 7 5 . 6 5 6 , 5 2}$ \\
\hline Total & $\mathbf{2 . 2 6 5 . 2 6 9 , 8 6}$ & $\mathbf{2 . 2 5 1 . 2 2 9 , 4 5}$ & $\mathbf{1 4 . 0 4 0 , 4 1}$ \\
\hline Área (ha) & $34.806 .308,37$ & $32.203 .560,58$ & $\mathbf{2 . 6 0 2 . 7 4 7 , 7 9}$ \\
\hline & $16.932,31$ & & \\
\hline
\end{tabular}

Quadro 1: Comparativo dos custos de produção da soja entre o método atual x ABC Fonte: Dados fornecidos pela empresa, ano agrícola (2012).

Percebe-se que o método atual utilizado na empresa (absorção), por utilizar a área plantada como forma de alocação dos custos e indiretos, ocasionou um valor acima de dois milhões de custos alocados a cultura de soja, que pelo método de custeio baseado em atividades, utilizando como direcionador dos custos as horas máquinas utilizadas nas atividades existentes na produção, que não são de responsabilidade desta cultura. Neste sentido, pode-se verificar que a cultura da soja no método atual absorveu custos que não a pertenciam, os quais na análise de resultados de cada cultura, impactavam diretamente no mesmo, fazendo com que essa cultura 
sempre fosse alvo de avaliação pelo baixo resultado apresentado, enquanto que em outras culturas apresentavam um melhor desempenho, o que não era verdadeiro, a diferença estava na forma de identificação e distribuição dos custos indiretos, o que pode ser visualizado a seguir.

\begin{tabular}{|c|c|c|c|}
\hline \multicolumn{4}{|c|}{ Custos da Cultura de Milho no Ano Agrícola de 2011/2012 em R\$ } \\
\hline Descrição & $\begin{array}{c}\text { Absorção } \\
\text { (atual) }\end{array}$ & ABC & Diferença \\
\hline Sementes & $837.535,05$ & $837.535,05$ & 0,00 \\
\hline Fertilizantes & $1.231 .407,88$ & $1.231 .407,88$ & 0,00 \\
\hline Defensivos Agrícolas & $360.720,01$ & $360.720,01$ & 0,00 \\
\hline Mão De Obra Variável & $44.490,22$ & $44.490,22$ & 0,00 \\
\hline Dransporte, Beneficiamento E Armazenagem & $82.945,89$ & $82.945,89$ & 0,00 \\
\hline Depreciações & $169.001,01$ & $169.001,01$ & 0,00 \\
\hline Amortizacão (corretivos) & $322.690,57$ & $322.690,57$ & 0,00 \\
\hline Arrendamentos & $31.747,31$ & $31.747,31$ & 0,00 \\
\hline Pulverização Aérea & $\mathbf{1 6 1 . 1 3 9 , 4 7}$ & $\mathbf{3 6 . 3 3 0 , 0 0}$ & $\mathbf{1 2 4 . 8 0 9 , 4 7}$ \\
\hline Combustíveis E Lubrificantes & $\mathbf{3 4 5 . 8 5 0 , 2 5}$ & $\mathbf{1 3 8 . 6 1 1 , 7 6}$ & $\mathbf{2 0 7 . 2 3 8 , 4 9}$ \\
\hline Máquinas, Veículos E Implem. Agrícolas & $\mathbf{4 9 7 . 5 3 7 , 0 5}$ & $\mathbf{1 9 1 . 1 5 6 , 2 3}$ & $\mathbf{3 0 6 . 3 8 0 , 8 2}$ \\
\hline Custos Gerais Variáveis & $\mathbf{2 9 1 . 5 9 4 , 3 2}$ & $\mathbf{1 6 7 . 7 6 5 , 0 2}$ & $\mathbf{1 2 3 . 8 2 9 , 3 0}$ \\
\hline Mão De Obra Fixa & $\mathbf{5 6 1 . 4 8 8 , 0 9}$ & $\mathbf{2 6 5 . 5 0 7 , 1 7}$ & $\mathbf{2 9 5 . 9 8 0 , 9 2}$ \\
\hline Custos Gerais Fixos & $\mathbf{2 6 3 . 2 8 0 , 8 6}$ & $\mathbf{1 2 3 . 7 8 0 , 9 7}$ & $\mathbf{1 3 9 . 4 9 9 , 8 9}$ \\
\hline Despesas Administrativas & $\mathbf{4 5 0 . 0 6 6 , 3 9}$ & $\mathbf{2 6 8 . 7 0 8 , 2 0}$ & $\mathbf{1 8 1 . 3 5 8 , 1 9}$ \\
\hline Total & $5.651 .494,37$ & $4.272 .397,29$ & $\mathbf{1 . 3 7 9 . 0 9 7 , 0 8}$ \\
\hline Área (ha) & $3.364,13$ & & \\
\hline
\end{tabular}

Quadro 2: Comparativo entre o custeio atual $x A B C$ na cultura do milho

Fonte: Dados fornecidos pela empresa, ano agrícola (2012).

Para a cultura do milho ocorre o mesmo fato que a cultura da soja, observa-se uma redução no valor da apropriação de custos pelo método $A B C$. Que justifica-se pela necessidade de menos atividades e tempo máquina no processo de produção. 
Os Benefícios do Custeio Baseado em Atividades na Gestão de Custos de Uma Empresa Agrícola Euselia Paveglio Vieira, Diego Rafael Winck, Roselaine Filipin

\begin{tabular}{|c|c|c|c|}
\hline \multicolumn{4}{|c|}{ Custos da Cultura de Algodão no Ano Agrícola de 2011/2012 em R\$ } \\
\hline Descrição & $\begin{array}{c}\text { Absorção } \\
\text { (atual) }\end{array}$ & ABC & Diferença \\
\hline Sementes & $436.643,43$ & $436.643,43$ & 0,00 \\
\hline Fertilizantes & $4.149 .824,07$ & $4.149 .824,07$ & 0,00 \\
\hline Defensivos Agrícolas & $5.278 .552,80$ & $5.278 .552,80$ & 0,00 \\
\hline Mão De Obra Variável & $594.062,97$ & $594.062,97$ & 0,00 \\
\hline Transporte, Beneficiamento E Armazenagem & $2.091 .333,05$ & $2.091 .333,05$ & 0,00 \\
\hline Depreciações & $746.697,06$ & $746.697,06$ & 0,00 \\
\hline Amortizacão (corretivos) & $1.393 .347,50$ & $1.393 .347,50$ & 0,00 \\
\hline Arrendamentos & $205.623,72$ & $205.623,72$ & 0,00 \\
\hline Pulverização Aérea & $\mathbf{2 1 4 . 1 7 3 , 7 6}$ & $\mathbf{5 7 2 . 4 8 3 , 0 9}$ & $-\mathbf{3 5 8 . 3 0 9 , 3 3}$ \\
\hline Combustíveis E Lubrificantes & $\mathbf{4 5 9 . 6 7 6 , 6 4}$ & $\mathbf{1 . 1 0 9 . 2 6 5 , 0 8}$ & $-\mathbf{6 4 9 . 5 8 8 , 4 4}$ \\
\hline Custos Gerais Variáveis & $\mathbf{6 6 1 . 2 8 6 , 6 7}$ & $\mathbf{1 . 5 3 4 . 7 3 6 , 8 6}$ & $-\mathbf{8 7 3 . 4 5 0 , 1 9}$ \\
\hline Mão De Obra Fixa & $\mathbf{3 8 7 . 5 6 3 , 9 7}$ & $\mathbf{9 8 2 . 6 9 6 , 4 7}$ & $\mathbf{- 5 9 5 . 1 3 2 , 5 0}$ \\
\hline Custos Gerais Fixos & $\mathbf{7 4 6 . 2 8 5 , 3 0}$ & $\mathbf{1 . 6 4 1 . 0 9 4 , 7 3}$ & $-\mathbf{8 9 4 . 8 0 9 , 4 3}$ \\
\hline Despesas Administrativas & $\mathbf{3 4 9 . 9 3 1 , 9 8}$ & $\mathbf{7 6 5 . 0 8 8 , 3 9}$ & $\mathbf{-} \mathbf{4 1 5 . 1 5 6 , 4 1}$ \\
\hline Total & $\mathbf{5 9 8 . 1 9 2 , 4 4}$ & $\mathbf{7 9 3 . 5 9 1 , 0 4}$ & $\mathbf{- 1 9 5 . 3 9 8 , 6 0}$ \\
\hline Área (ha) & $18.313 .195,36$ & $22.295 .040,26$ & $\mathbf{3 . 9 8 1 . 8 4 4 , 9 0}$ \\
\hline & $4.471,33$ & & \\
\hline
\end{tabular}

Quadro 3: Comparativo entre o custeio atual x $A B C$ na cultura do algodão.

Fonte: Dados fornecidos pela empresa, ano agrícola (2012).

$\mathrm{Na}$ produção do algodão, observa-se que o modelo $\mathrm{ABC}$ aloca um valor de aproximadamente quatro milhões a mais que o método que utilizou o direcionador pela área plantada. Justifica-se o fato devido à cultura do algodão que necessita de um número maior de atividades de preparo de solo, aplicações de defensivos e fertilizantes, que são apontados pelo método de custeio baseado em atividades. 
Os Benefícios do Custeio Baseado em Atividades na Gestão de Custos de Uma Empresa Agrícola Euselia Paveglio Vieira, Diego Rafael Winck, Roselaine Filipin

\begin{tabular}{|c|c|c|c|c|c|c|}
\hline \multicolumn{7}{|c|}{ Comparação do Resultado das Culturas de Soja, Algodão e Milho no Ano Agrícola de 2011/2012 } \\
\hline & \multicolumn{3}{|c|}{ Soja } & \multicolumn{3}{|c|}{ Milho } \\
\hline Descrição & $\begin{array}{c}\text { Absorção } \\
\text { (Atual) }\end{array}$ & $\mathrm{ABC}$ & Diferença & $\begin{array}{c}\text { Absorção } \\
\text { (Atual) }\end{array}$ & $A B C$ & Diferença \\
\hline Receita Bruta & $65.363 .244,89$ & $65.363 .244,89$ & 0,00 & $6.123 .516,00$ & $6.123 .516,00$ & 0,00 \\
\hline ( - ) Deduções & $2.115 .806,82$ & $2.115 .806,82$ & 0,00 & $565.935,00$ & $565.935,00$ & 0,00 \\
\hline Receita Líquida & $63.247 .438,07$ & 63.247.438,07 & 0,00 & $5.557 .581,00$ & $5.557 .581,00$ & 0,00 \\
\hline ( - ) Custo Variável & $21.618 .791,81$ & $19.904 .569,45$ & $1.714 .222,36$ & $3.853 .220,13$ & $3.090 .962,06$ & $762.258,07$ \\
\hline ( - ) Custo Fixo & $10.922 .246,69$ & 10.047.761,68 & $874.485,01$ & $1.348 .207,84$ & $912.727,03$ & $435.480,81$ \\
\hline Resultado Bruto & $30.706 .399,57$ & $33.295 .106,94$ & $\begin{array}{c}- \\
2.588 .707,37\end{array}$ & $356.153,03$ & $1.553 .891,91$ & $\begin{array}{c}- \\
1.197 .738,88\end{array}$ \\
\hline $\begin{array}{c}\text { Despesas } \\
\text { Administrativas }\end{array}$ & $2.265 .269,85$ & $2.251 .229,45$ & $14.040,40$ & $450.066,38$ & $268.708,20$ & $181.358,18$ \\
\hline Resultado Líquido & $28.441 .129,72$ & $31.043 .877,49$ & $\begin{array}{c}- \\
2.602 .747,77\end{array}$ & $-93.913,35$ & $1.285 .183,71$ & $\begin{array}{c}- \\
1.379 .097,06\end{array}$ \\
\hline & \multicolumn{3}{|c|}{ Algodão } & & & \\
\hline Descrição & $\begin{array}{c}\text { Absorção } \\
\text { (Atual) }\end{array}$ & $A B C$ & Diferença & & & \\
\hline Receita Bruta & $33.521 .505,75$ & $33.521 .505,75$ & 0,00 & & & \\
\hline ( - ) Deduções & $1.675 .334,11$ & $1.675 .334,11$ & 0,00 & & & \\
\hline Receita Líquida & $31.846 .171,64$ & $31.846 .171,64$ & 0,00 & & & \\
\hline ( - ) Custo Variável & $14.273 .117,36$ & $16.749 .597,82$ & $\begin{array}{c}- \\
2.476 .480,46\end{array}$ & & & \\
\hline ( - ) Custo Fixo & $3.441 .885,56$ & $4.751 .851,40$ & $\begin{array}{c}- \\
1.309 .965,84\end{array}$ & & & \\
\hline Resultado Bruto & $14.131 .168,72$ & $10.344 .722,42$ & $3.786 .446,30$ & & & \\
\hline $\begin{array}{c}\text { Despesas } \\
\text { Administrativas }\end{array}$ & $598.192,44$ & $793.591,04$ & $-195.398,60$ & & & \\
\hline Resultado Líquido & 13.532.976,28 & $9.551 .131,38$ & $3.981 .844,90$ & & & \\
\hline
\end{tabular}

Quadro 4: Comparativo entre resultado do custeio atual x $A B C$ nas culturas.

Fonte: Dados fornecidos pela empresa, ano agrícola (2012). 
No quadro 4, observa-se que a cultura do algodão, pelo método $A B C$, teve uma redução no resultado. A cultura do milho, saiu de uma situação de resultado negativo para apresentar com o modelo $A B C$ um resultado positivo. A cultura da soja sofreu uma alavancagem de resultado com o $\mathrm{ABC}$.

Pode-se concluir que o método atual de custeio, quando aplicados em empresa agrícola com mais de uma cultura, e que utiliza como base de distribuição dos custos indiretos a área plantada, as culturas que utilizam a maior área, são as que apropriam um maior custo, devido a absorção dos custos indiretos. Então, a partir destas considerações pode-se apontar alguns benefícios obtidos pela empresa agrícola com a utilização do custeio baseado em atividades frente a métodos tradicionais utilizados, considerando que o custeio $\mathrm{ABC}$ é uma metodologia de forte embasamento conceitual, mas não é de fácil implementação e demanda um forte investimento em sistemas de informações e procedimentos.

Dentre os benefícios, destaca-se o fato que os custos dos produtos são apropriados conforme as atividades necessárias para a sua produção, onde os custos indiretos são consumidos por estas atividades. Dessa forma, permite a análise das atividades necessárias para a produção e dentre elas definir quais são as que realmente agregam valor ao produto, podendo-se diminuir ou eliminar as atividades que não agregam valor, com tomadas de decisões de longo prazo. Também fica evidente na avaliação dos resultados que no custeio $A B C$, apresenta os valores efetivamente gastos em cada cultura, apresentando o desempenho real de cada uma, com suas respectivas receitas, custos e despesas, subsidiando a gestão no gerenciamento de cada atividade de cada cultura. Como já destacado não, é necessária a implantação do sistema de forma completa na empresa agrícola.

\section{CONCLUSÃO}

Devido as grandes mudanças tecnológicas e de mercado que a empresa agrícola vem passando nos últimos anos, sistemas de custos tradicionais talvez não 
atendam todas as demandas por informações necessárias à gestão da empresa. Métodos como o custeio por absorção pode levar a tomadas de decisões errôneas no negócio agrícola. Para evitar isso, os gestores precisam de uma melhor informação sobre os custos realizados e saber quais as atividades que demandam os recursos da cultura produzida, avaliando a sua importância dentro do processo produtivo, para que se mantenha, desenvolva ou desative uma atividade.

Para que uma empresa agrícola adote um sistema de custeio baseado em atividade, se faz necessário levar em consideração que as informações geradas serão utilizadas para informações gerenciais e legais. Geralmente o método de custeio utilizado pela empresa agrícola é válido e prático para o Balanço e Demonstrativo de Resultado do Exercício, e é aceito pela Receita Federal que o exige para cálculo de cobranças de impostos e avaliações de estoque, mas não é uma ferramenta tão eficaz de gestão para tomada de decisões, pois em muitos casos induz a distorções e a imprecisões de resultados. Aponta-se também uma dificuldade na implantação do custeio $A B C$ em função de sua complexidade e detalhamento, já que a empresa já deve ter um sistema de custos, padronizações, procedimentos e controles fixados na cultura empresarial, e que o seu custo de implantação é alto, em função de que vai demandar ajustes nos sistemas já existentes ou aquisição de novos, treinamento para os colaboradores e usuários das informações.

Outro ponto a ser considerado para a utilização do modelo $A B C$ é que na elaboração do orçamento de custeio deve-se adotar a sistemática das atividades envolvidas em cada cultura, orçando-as pelos fatores presentes na atividade, como horas máquina, horas homem, entre outros. Assim, consegue-se a fixação prévia do resultado que será obtido ao término de ano agrícola, bem como o acompanhamento momentâneo de possíveis desvios entre o custo das atividades orçadas e das realizadas.

Os benefícios destacados com a utilização do modelo de custeio baseado em atividades são a apropriação dos custos dos produtos conforme as atividades necessárias para a sua produção, onde os custos indiretos são consumidos por estas 
atividades. Permitindo-se a análise das atividades necessárias para a produção e dentre elas definir quais são as que realmente agregam valor ao produto, podendo-se diminuir ou eliminar as atividades que não agregam valor, com tomadas de decisões de longo prazo. Também fica evidente na avaliação dos resultados que no custeio $A B C$, apresenta os valores efetivamente gastos em cada cultura, apresentando o desempenho real de cada uma, com suas respectivas receitas, custos e despesas, subsidiando a gestão no gerenciamento de cada atividade de cada cultura. No entanto, nenhum método de custeio apresenta precisamente os custos de produção quando da existência de mais de um produto.

Nota-se no estudo de caso que, com a implantação de conceitos do custeio baseado por atividades na empresa, culturas que antes eram vistas com custo elevado de produção, como a soja, que em análises poder-se-ia tomar a decisão de que sua produção era inviável financeiramente, visto que acabava absorvendo parte dos custos das outras culturas, como o algodão, isso em virtude da maior área de cultivo. Como o método $A B C$, pode-se alocar os custos conforme as atividades demandadas pelas culturas, assim, demonstrando as culturas com maior custo devido a quantidade e ao nível de elaboração das atividades existentes na produção. Conclui-se então que o custeio baseado em atividades, quando implantado em sua totalidade, ou mesmo parcialmente, traz benefícios aos gestores da empresa agrícola. E sabendo que sua utilização é apropriada quando a empresa produz mais de um produto e para empresa de grande porte. No processo de implantação, pode-se mesclar o método $A B C$ com outra forma de apropriação, seja ele variável ou absorção.

\section{REFERÊNCIAS}

BORNIA, Antonio Cesar Bornia. (2010). Análise Gerencial de Custos. (3 ed.). São Paulo: Atlas, pp. 214.

FURASTÉ, Pedro Augusto. (2003). Normas Técnicas para o Trabalho Científico: Explicitação das Normas da ABNT. (12 ed.). Porto Alegre: s.n., pp. 150. 
GIL, Antonio Carlos. (2002). Como Elaborar Projetos de Pesquisa. (4 ed.). São Paulo: Atlas, pp. 175.

LEONE, George; LEONE, Rodrigo. (2010). Curso de Contabilidade de Custos. (4 ed.). São Paulo: Atlas, pp. 480.

MARION, José Carlos; DIAS, Reinaldo; TRALDI, Maria Cristina. (2002). Monografia para os Cursos de Administração, Contabilidade e Economia. São Paulo: Atlas, pp. 135.

MARTINS, Eliseu; ROCHA, Welington. (2010). Métodos de Custeio Comparados. São Paulo: Atlas, pp. 192.

NAKAGAWA, Masayuki. (2001). ABC Custeio Baseado em Atividades. (2 ed.). São Paulo: Atlas, pp. 95.

SANTOS, Gilberto José dos; MARION, José Carlos; SEGATTI, Sonia. (2009). Administração de Custos na Agropecuária. (4 ed.). São Paulo: Atlas, pp. 168.

VERGARA, Sylvia Constant. (2004). Projetos e Relatórios de Pesquisa em Administração. (5 ed.). São Paulo: Atlas, pp. 96.

Data de Submissão: 15/07/2014

Data de Aceite: 22/03/2015 